\title{
Effect of extraction methods and temperature preservation on total anthocyanins compounds of Peristrophe bivalvis L. Merr leaf
}

\author{
Nguyen Minh Thuy ${ }^{1 *}$ (D), Dao Huynh Ngoc Han ${ }^{1}$, Vo Quang Minh ${ }^{2}$ (D), Ngo Van Tai ${ }^{1}$ (D) \\ ${ }^{1}$ Department of Food Technology, College of Agriculture, Can Tho University, Can Tho, Vietnam. \\ ${ }^{2}$ Department of Land Sources, College of Environment and Natural Resources, Can Tho University, Can Tho, Vietnam.
}

\begin{tabular}{l}
\hline ARTICLE INFO \\
\hline Article history: \\
Received on: August 22, 2021 \\
Accepted on: October 13, 2021 \\
Available Online: February 15, 2022 \\
\hline
\end{tabular}

Key words:

Anthocyanin, extraction methods, kinetic, Peristrophe bivalvis L.

Merr. leaf, preservation

\begin{abstract}
This paper proposes anthocyanins extraction from Peristrophe bivalvis L. Merr. ("lá cẩm") and preservation. Experiments were performed in water as a solvent using two different extraction methods [conventional extraction (CE) and microwave-assisted extraction (MAE)], including different solvent-to-raw material ratios, temperatures/microwave power, and times of extraction. The total anthocyanin in the extract was analyzed by UV-Vis. Multiple regression analysis was applied to analyze the influence of factors and select the optimal parameters for each extraction process. The influence of storage conditions on the quality of extracts from "lá cẩm" leaves was controlled. It was observed that the ratio of solvent and fresh leaf used, temperature/ microwave power, and extraction time all affected the anthocyanin content recovered from the extract when using different extraction techniques. The MAE technique gave superior results compared to the CE method. The solvent used was slightly higher and the extraction time was 6.2 times shorter than that of the CE method. The optimal parameters of each extraction technique are selected. With the CE method, the solvent-to-fresh leaf ratio was 11.22:1; the optimum temperature and time were $88^{\circ} \mathrm{C}$ and 27.21 minutes resulting in the anthocyanin content in the extract being $25.61 \mathrm{mg} / \mathrm{g}$ dry weight basic (db). Meanwhile, with the MAE method, the solventto-fresh leaf ratio used was 10.83:1 (v/w), the microwave power and the optimal extraction time were $600 \mathrm{~W}$ and 4.39 minutes, and the obtained extract had an anthocyanin content of $30.97 \mathrm{mg} / \mathrm{g} \mathrm{db}$. In addition, the extract was best preserved in the dark and the storage temperature was $-9^{\circ} \mathrm{C}$. The remaining anthocyanin content after 30 days of storage was $92.35 \%$. The anthocyanin degradation kinetics was also analyzed. Changes in total anthocyanin followed a zero-order reaction kinetic model. The potential of the half-life of anthocyanin was 221,114 , and 19 days at $-9^{\circ} \mathrm{C}, 4^{\circ} \mathrm{C}$, and $28^{\circ} \mathrm{C}$, respectively.
\end{abstract}

\section{INTRODUCTION}

Dicliptera tinctoria is the common name for a species in the family Acanthaceae (synonym Peristrophe bivalvis (L.) Merr. and Peristrophe roxburghiana). It can be called the magenta plant or the tree "lá cẩm" in Vietnamese. The leaf extract is used to give a beautiful purple color to some Vietnamese foods, especially in cakes, sticky rice, and certain types of desserts. In traditional Chinese medicine, it has been used in the decoction of extracts to treat ailments including cough, dysentery, diarrhea, and bronchitis [1]. Besides its healing properties, it

\footnotetext{
*Corresponding Author

Nguyen Minh Thuy, Department of Food Technology, College of Agriculture, Can Tho University, Can Tho, Vietnam.E-mail:nmthuy@ ctu.edu.vn
}

has also been identified as a potential source of anthocyanins. Anthocyanins have been shown to have health benefits due to the presence of flavonoids with strong antioxidant activity in the metabolic reaction [2]. Several authors have also reported on the antioxidant and antimicrobial potential of anthocyanins [3-5]. As the range of applications is increasing and the need to obtain these compounds increases due to their inherent safety and properties, the most common way to obtain anthocyanins is to extract them from the plant. In addition, with increasing consumer awareness of the necessary healthy eating habits, the industry has been trying to find sources of all-natural additives that are completely safe but can also carry some health benefits. Anthocyanins may be one of a group of compounds that satisfy these properties. Therefore, anthocyanins have attracted the attention of the scientific community largely. Natural anthocyanin 
pigments with high antioxidant capacity and biological potential will be a good opportunity for the development of new food additives and functional foods. Among foods containing high levels of anthocyanin pigments, "lá cẩm" that is being grown very popularly in Vietnam can also bring about this potential. However, the problems that need special attention are the extraction technique and how to stabilize and prolong the shelf life of this compound after collection. Among the extraction methods used, microwave-assisted extraction (MAE) offers more advantages such as reduced thermal gradient, increased extraction yield, faster heating, and also reduced device size. It is considered as a new technology for obtaining useful compounds from plant biomass [6,7]. Furthermore, the extraction time of bioactive compounds using the MAE technique is less than that of conventional extraction (CE) methods. This technique also uses fewer organic solvents, so it can be considered as a green technology [8]. The aim of this study is to investigate the extraction techniques (CE and MAE) of total anthocyanins in "lá cẩm" grown at Can Tho University, Vietnam. Despite the great potential of natural anthocyanins for use as food colorants, their use has been limited due to their relative instability [9]. The shelf life of the extract under different storage conditions and kinetics degradation were also determined simultaneously.

\section{MATERIALS AND METHODS}

\subsection{Sample Preparation}

Peristrophe bivalvis L. Merr. leaves are grown at the Can Tho University, Vietnam. Leaves were harvested in the largest stage (length: 16-18 cm). After harvesting, the leaves were washed with running tap water and drained. The study was conducted in two stages: the extract was obtained first by different methods (CE and MAE) with influencing factors, material-to-water ratio, different temperatures, and extraction time, while the second was different conditions for storage of the obtained extract.

This study was conducted from June 2020 to May 2021 at the Department of Food Technology, Can Tho University, Vietnam.

\subsection{Extraction Procedures}

For each treatment, the fresh leaves were ground using a grinder (model SM-450, Lab Sample Mill with separated cup$300 \mathrm{CC}, \mathrm{UK}) .10 \mathrm{~g}$ of the ground leaves was taken and placed in a $250 \mathrm{ml}$ Erlenmeyer flask to perform different extraction methods.

\subsubsection{Conventional extraction (CE)}

Extraction was started by mixing ground leaves in water, using a $250 \mathrm{ml}$ Erlenmeyer flask with different ratios of solvent (water) to leaves of 4:1, 6:1, 8:1,10:1, and 12:1, extraction temperatures $\left(80^{\circ} \mathrm{C}-100^{\circ} \mathrm{C}\right.$, interval $\left.10^{\circ} \mathrm{C}\right)$, and times $(10-40$ minutes, sampling every 10 minutes). Each experiment was performed three times.

\subsubsection{Microwave- assisted extraction (MAE)}

According to the preliminary study (data not shown), the extraction process was carried out in a microwave oven (LG MS2595DIS, Korea) with a fixed power level of $600 \mathrm{~W}$ with the ratio of solvent (water) to raw material (leaves) as described above
(CE method). However, with this method, a shorter extraction time was conducted, only 3-6 minutes (sampling every minute). Each experiment was performed three times.

All the extracts obtained from the different methods were then centrifuged (Z232K, Hermle, Germany) for 30 minutes at $13,000 \mathrm{~g}$ at room temperature to obtain the supernatant. The clear liquid was obtained after being passed through the filter paper (Whatman No. 4, UK). The extract was kept in a glass vial covered with aluminum foils under subdued light for further analysis.

\subsection{Preservation of Extraction}

The extract samples were sealed in $2 \mathrm{ml}$ Eppendorf ${ }^{\circledR}$ Safe-Lock microcentrifuge tubes (Merck, Germany) and stored at different temperatures and conditions, including $-9^{\circ} \mathrm{C}$ and $4^{\circ} \mathrm{C}$, and kept at ambient temperature $\left(28^{\circ} \mathrm{C} \pm 2^{\circ} \mathrm{C}\right)$ in the dark and normal condition. The kinetics of anthocyanin degradation was determined for 30 days.

\subsection{Determination of Total Anthocyanin Content (TAC)}

The TAC was quantified using the $\mathrm{pH}$-differential method as described by Guisti and Wrolstad [10]. Briefly, $1 \mathrm{ml}$ extracted solution reacted with a potassium chloride buffer $(0.0025 \mathrm{M}, \mathrm{pH} 1.0)$ and sodium acetate buffer $(0.4 \mathrm{M}, \mathrm{pH} 4.5)$. The mixture was incubated for 15 minutes. An Agilent Cary 60 UV-Vis spectrophotometer (USA) was used for measurements at 510 and $700 \mathrm{~nm}$ against a blank cell filled with distilled water. The calculation of TAC was expressed as cyanidin-3-glucoside equivalents, using Equation 1.

Anthocyanin content $(\mathrm{mg} / \mathrm{g})=\frac{A \times \mathrm{MW} \times \mathrm{DF} \times V \times 1,000}{a \times 1 \times m}$,

where $A$ is the absorbance, MW is the molecular weight of cyanidin-3-glucoside (449.2 g/mol), DF is the dilution factor, $V$ is the solvent volume $(\mathrm{ml}), \mathrm{a}$ is the molar absorptivity $(26,900$ $\left.1 . \mathrm{mol}^{-1} \cdot \mathrm{cm}^{-1}\right)$, and 1 is the cell path length $(1 \mathrm{~cm})$.

\subsection{Data Analysis}

\subsubsection{Anthocyanin degradation kinetics at different storage temperatures}

The stability of anthocyanins was reported in terms of degradation rate and half-life. It was found that the degradation kinetics of anthocyanins in the case of extraction from the butterfly pea flower followed the zero-order reaction (Equation 2) which is reported by Charurungsipong et al. [11]. The anthocyanin content at a given time at any temperature and its half-life was determined using Equation (3).

$$
\begin{aligned}
& C=-k_{t}+C_{O} \\
& t_{1 / 2}=C_{O} / 2_{k}
\end{aligned}
$$

where $C_{\mathrm{o}}$ is an initial anthocyanin content $(\mathrm{mg} / \mathrm{l}), C_{\mathrm{t}}$ is an anthocyanin content (mg/l) at storage time $t$ (days), $k$ is the degradation rate constant of anthocyanin $\left(\mathrm{day}^{-1}\right)$, and $t_{1 / 2}$ is the half-life of anthocyanins (day). 
The activation energy $\left(E_{\mathrm{a}}\right)$, a measure of temperature dependence on anthocyanin degradation, can be predicted appropriately using the Arrhenius equation [12]:

$$
k=k_{o} \exp \frac{-E a}{R T},
$$

where $k$ is rate constant $\left(\right.$ day $\left.^{-1}\right), k_{\mathrm{o}}$ is the frequency factor (per day), $E_{\mathrm{a}}$ is the activation energy $\left(\mathrm{J}^{\mathrm{m}} \mathrm{mol}^{-1}\right), R$ is the universal gas constant $\left(8.314 \mathrm{~J}^{\mathrm{mol}}{ }^{-1} \cdot \mathrm{K}^{-1}\right)$, and $\mathrm{T}$ is the absolute temperature in Kelvin (K).

\subsubsection{Statistical analysis}

Statistical analysis was conducted using STATGRAPHICS Centurion XIX (USA) to fit the model to the observed data. The proposed model for each response $(Y)$ was

$$
Y=b_{o}+\sum_{n=1}^{3} b_{n} X_{n}+\sum_{n=1}^{3} b_{n n} X_{n}^{2}+\sum_{n \neq m=1}^{3} b_{n m} X_{n} X_{m},
$$

where $b_{\mathrm{o}}$ is the $Y$-intercept (constant), $b_{\mathrm{n}}$ is the regression coefficient for the linear effect of $X_{\mathrm{n}}$ on $Y, b_{\mathrm{nn}}$ and $b_{\mathrm{nm}}$ are the regression coefficients for the quadratic effect on $Y$, and $X_{\mathrm{n}}$ and $X_{\mathrm{m}}$ are independent values.

To select the acceptable condition, the multiple regression analysis was used for the data from each reference, such as water-to-material ratio, extraction temperature, and time. In the multiple regression analysis, the TAC was defined as the dependent variable and the water-to-material ratio, temperature, and time were defined as the independent variables. The reference equation was selected to fit the data based on the $R^{2}$ value obtained from the multiple regressions analysis.

\section{RESULTS AND DISCUSSION}

\subsection{Optimization Leaves Extraction Conditions}

\subsubsection{CE}

The TAC in the extract was obtained differently when the leaves were extracted under different conditions. The TAC obtained by the CE method ranged from 9.43 to $28.57 \mathrm{mg} / \mathrm{g}$ dry weight basic (db). Anthocyanins are the common water-soluble pigments in plants, comprising more than 540 species that vary in color such as red, orange, purple, and blue [13]. However, anthocyanins instability due to exposure to factors such as $\mathrm{pH}$, the presence of oxygen, light, heat, and water activity results in the degradation or destruction of these compounds [14]. Three factors that significantly affect the extraction process are solvent-to-solid ratio, temperature, and time (Fig. 1). The extraction efficiency was evaluated by the obtained TAC in the extract. The results may be due to the physical process of dissolving biologically active substances into the solvent. As the amount of solvent increases, there is an opportunity for bioactive compounds to interact with the solvent resulting in higher permeability. When the solvent-tomaterial ratio is large differently, the gradient pressure difference between the solvent and the solutes becomes large due to more bioactive substances that can be significantly dissolved [9]. At the solvent-to-material ratio of $4: 1$, the solvent volume is too low, leading to difficult-to-dissolve anthocyanin constituents.
Main Effects Plot for Anthocyanin

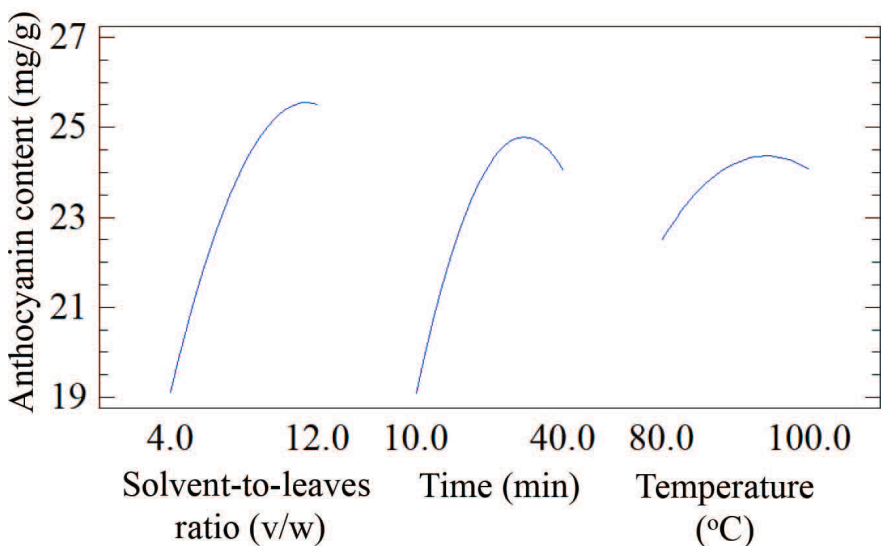

Figure 1: The influence of independent variables on anthocyanin content in extract under CE.

Therefore, increasing the solvent-to-material ratio, the obtained TAC also increases. However, when extracting with too much solvent while the TAC in the raw material is a constant number, it would quickly lead to a balance between the phases making the extraction efficiency not increase. The yield of the compounds to be extracted will not continue to increase once the extraction solution has reached equilibrium [15].

The obtained result was similar to the effect of solventto-material ratio on the extraction of anthocyanins from butterfly pea flowers by Thuy et al. [16]. The results also indicated that TAC in the leaf extract increased when the extraction temperature was increased from $80^{\circ} \mathrm{C}$ to $90^{\circ} \mathrm{C}$, but when the extraction temperature continued to increase to $100^{\circ} \mathrm{C}$, the TAC decreased. The reason is that heat treatment increases the solubility and diffusion of compounds, decreases solvent viscosity, and increases mass transfer and solvent penetration into cells [17]. High temperature can reduce cell barriers by weakening cell walls and membranes, resulting in easier contact of the solvent with substances, increasing the extraction capacity [18]. However, the stability of anthocyanins and other food colorants decreases with increasing temperature [19]. A temperature that is too high makes the $-\mathrm{OH}$ groups in anthocyanin molecules less stable and degraded, resulting in reducing anthocyanin content. In addition, the TAC obtained in the extract tended to increase with increasing extraction time from 10 to 30 minutes. When further increasing the extraction time to over 30 minutes, the TAC obtained was not significantly increased; however, the degradation phenomenon occurred. When the extraction time was extended to 40 minutes, the TAC decreased in the extract. The previous results showed that a too short or too long time would not yield a high TAC. The prolonged time increases the contact between the raw materials and the solvent; the active ingredients are easier to move to the environment. However, if the extraction time is too long, anthocyanins in the solvent are also easily oxidized by the factors of temperature and atmospheric oxygen [20]. The obtained results were similar to the study on the influence of time on the extraction of anthocyanins from Bauhinia purpurea by Marpaung et al. [21]. The TAC was highest when extraction was at $85^{\circ} \mathrm{C}$ and extraction time 25 minutes. The driving force of the extraction process is the 
Table 1: Analysis of variance for anthocyanin content in extract under different $\mathrm{CE}$ conditions.

\begin{tabular}{lccccc}
\multicolumn{1}{c}{ Source } & Sum of squares & Df & Mean square & $\boldsymbol{F}$ ratio & $\boldsymbol{p}$ value \\
Model & $2,430.66$ & 9 & 270.073 & 86.55 & 0.0000 \\
Residual & 530.501 & 170 & 3.1206 & - & - \\
Total (Corr.) & $2,961.16$ & 179 & - & - & - \\
\hline
\end{tabular}

difference in the concentration of components in the raw material and in the solvent [22]. The influence of the solvent-to-solid ratio, extraction temperature, and time on the TAC determined by the differential $\mathrm{pH}$ method is shown in Figure 2. The independent, two-way interactions and square of the factors influenced the response variable $(p<0.05)$. The coefficient of variation was less than $5 \%$, which means a correct development of the experiment procedure and good control of the extrinsic variation [23]. The results showed that all nine effects had $p$ values less than 0.05 , showing a significant effect on TAC in the extract at the $95 \%$ confidence level.

The analysis showed the results of fitting a multiple linear regression model to describe the relationship between TAC in extract and nine independent variables (Table 1). It can be seen that the $p$ value of the model in the analysis of variance (ANOVA) table is less than 0.05, indicating that the relationship between the variables was statistically significant at the $95.0 \%$ confidence level. The $R^{2}$ statistic indicates that the model as fitted explains $82.08 \%$ of the variability in the TAC. The adjusted $R^{2}$ statistic, which is more suitable for comparing models with different numbers of independent variables, is $81.13 \%$. The standard error of the estimate (SEE) shows the standard deviation of the residuals to be 1.77 . The equation of the fitted model is found in Equation (6).

$$
\begin{aligned}
& \text { Anthocyanin }(\mathrm{mg} / \mathrm{g})=-127.42+6.29 \mathrm{~A}+1.71 \mathrm{~B}+ \\
& 2.142 \mathrm{C}-0.12 \mathrm{~A}^{2}-0.04 \mathrm{AB}-0.029 \mathrm{AC}-0.007 \mathrm{BC}- \\
& 0.0117 \mathrm{~B}^{2}-0.009 \mathrm{C}^{2} \\
& R^{2}=82.08 \% ; R^{2} \text { (adj. for d.f.) }=81.13 \% ; \mathrm{SEE}=1.77 .
\end{aligned}
$$

The estimated response surface was also obtained (Fig. 3) and the highest predicted anthocyanin content was reached at $25.61 \mathrm{mg} / \mathrm{g}$ when the leaves extract was obtained at the solvent-to-solid ratio of $11.22(\mathrm{v} / \mathrm{w})$ at approximately $88^{\circ} \mathrm{C}$ for 27.21 minutes.

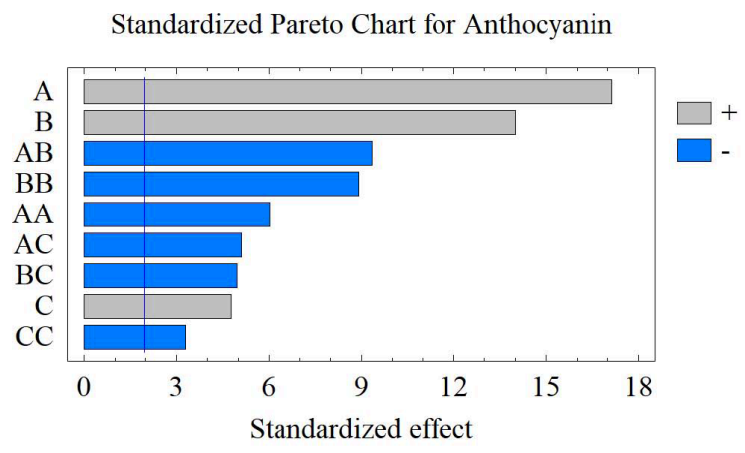

Figure 2: The standardized effect of factor on anthocyanin content under CE technique. $A$ is solvent-to-fresh leaves ratio $(\mathrm{v} / \mathrm{w}) ; B$ is extraction time (minute); $C$ is extraction temperature $\left({ }^{\circ} \mathrm{C}\right)$.

\subsubsection{MAE}

The TAC obtained in the extract during MAE was in the range of $17.35-30.64 \mathrm{mg} / \mathrm{g} \mathrm{db}$ (Fig. 4). Similar to the extraction under traditional conditions, the TAC obtained gradually increased with increasing the solvent-to-solid ratio. The increase in TAC is due to the influence of heat generated in the microwave. The radiation causes the cell wall to break down to release anthocyanins that exist in the cell towards the solvent, reducing the solvent's viscosity, thereby increasing the speed's effective diffusivity of the solvent and solute. However, the temperature of the mixture was increased to a very high degree with prolonged use of the microwave, leading to the decomposition of heat-labile compounds, a result consistent with the study of Tsai et al. [24] where anthocyanins are not suitable for maintenance at elevated temperatures. The microwave power can reduce antioxidant content [25], causing anthocyanin degradation in the later stage of extraction due to high temperature [26]. When extracting for too short a time, the temperature affects the solvent and the material may not be enough to dissolve the required substances.

However, if the extraction process continues for a longer time, the obtained anthocyanin content is significantly reduced. This may be due to the heat accumulation that causes a local high temperature in the later stages of the microwave process, causing destruction of the anthocyanin structure, which accelerates anthocyanin resolution [26]. This result is quite similar to that reported by Liazid et al. [27] that the optimal time for extraction of the TAC from grape skins was 5 minutes (microwave power $500 \mathrm{~W}$ ). The Pareto chart showed each of the estimated effects and interactions and indicated that there were $95.0 \%$ confidence intervals for the estimates (Fig. 5).

The predicted model was also observed with a high correlation $\left(R^{2}=96.5 \%\right)$. Moreover, the ANOVA table (Table 2) also indicated that the model has a $p$ value less than 0.05 , which confirmed the $95.0 \%$ confidence level [Eq. (7)].

$$
\begin{aligned}
& \text { Anthocyanin }(\mathrm{mg} / \mathrm{g})=-18.10+5.04 \mathrm{~A}+9.75 \mathrm{~B}- \\
& 0.188 \mathrm{~A}^{2}-0.22 \mathrm{AB}-0.84 \mathrm{~B}^{2} \\
& R^{2}=96.5 \% ; R^{2} \text { (adj. for d.f.) }=96.18 \% ; \mathrm{SEE}=0.7 .
\end{aligned}
$$

The plot shows the effect of factors on the TAC that was observed (Fig. 6). In addition, the statistical analysis indicated that the optimal conditions for the extraction process under microwave were the solvent-to-solid ratio of 10.83 for 4.39 minutes. Under these conditions, the TAC reached $30.60 \mathrm{mg} / \mathrm{l}$.

\subsubsection{Comparison of the two extraction techniques (CE and MAE)}

The optimal technical parameters and TAC obtained from extraction by the CE and MAE methods are shown in Table 3 . The CE method had the advantage of being relatively simple and

Table 2: Analysis of variance for anthocyanin in extracts under MAE.

\begin{tabular}{lccccc}
\multicolumn{1}{c}{ Source } & $\begin{array}{c}\text { Sum of } \\
\text { squares }\end{array}$ & Df & $\begin{array}{c}\text { Mean } \\
\text { square }\end{array}$ & $\boldsymbol{F}$ ratio & $\boldsymbol{p}$ value \\
Model & 702.514 & 5 & 140.503 & 283.52 & 0.0000 \\
Residual & 26.7607 & 54 & 0.495569 & - & - \\
Total (Corr.) & 729.274 & 59 & - & - & - \\
\hline
\end{tabular}



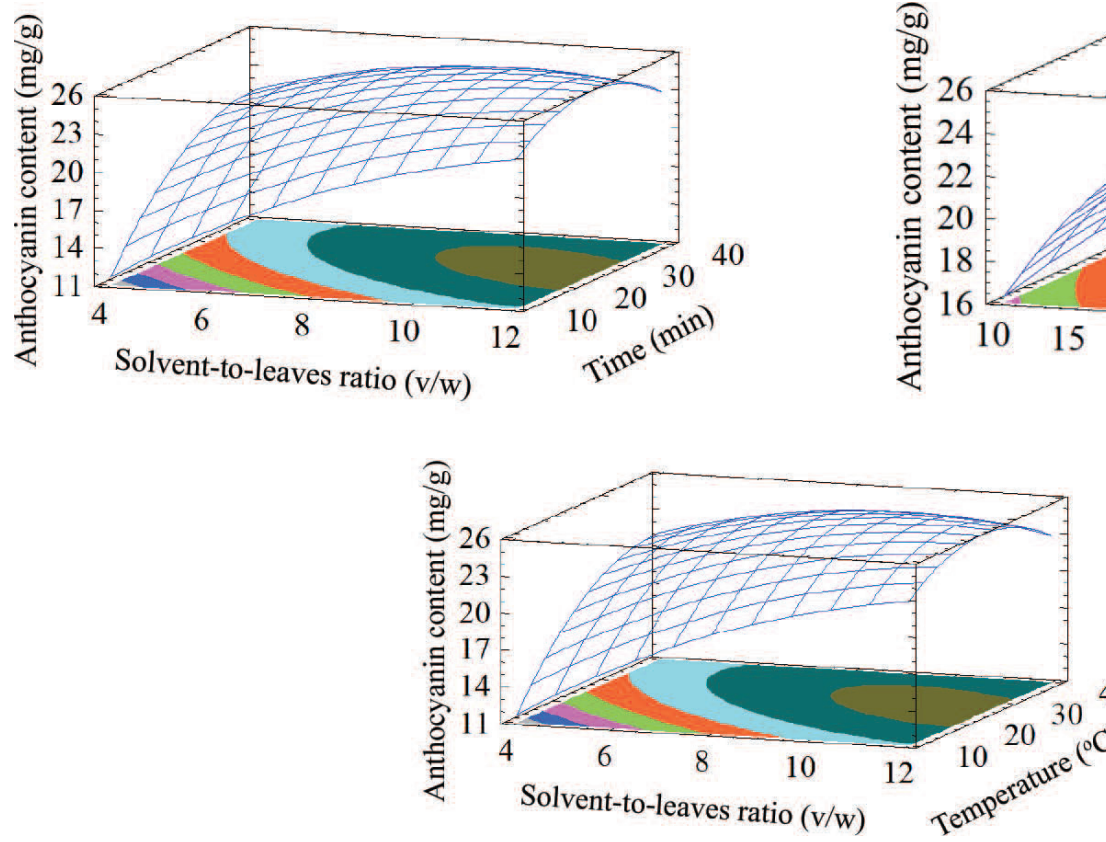

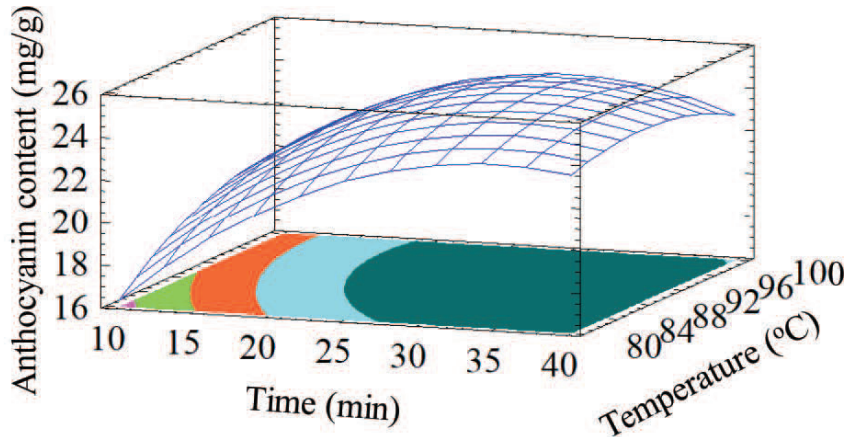

$11.0-13.0$

$13.0-15.0$

$15.0-17.0$

$17.0-19.0$

$19.0-21.0$

$40 \quad 21.0-23.0$

C) $23.0-25.0$

$25.0-27.0$

$27.0-29.0$

Figure 3: Estimated response surface plot for anthocyanin in extracts under CE.

easy to conduct [28]. However, the extraction time is usually quite long. MAE has advantages such as reduced processing time, lower solvent demand, but higher energy and yield [29,30]. The analysis results showed that the extraction of anthocyanins from the leaves by the MAE method improved the TAC obtained and reduced the extraction time by 6.2 times compared to the results of the $\mathrm{CE}$ method. During CE, heat transfer occurs from the heated medium to the cell's interior, while the mass transfer of solutes proceeds in the opposite direction. In the case of MAE, both the temperature and the mass gradient act in the same direction towards the outside of the cell, allowing for increased extraction efficiency of highvalue compounds and reduced process time [31].

\subsection{Effect of Storage Conditions on Stability of Anthocyanin in Leaves Extracts}

Both temperature and light also affect the TAC remaining in the leaf extract during storage. The obtained results indicated that, after 30 days of storage, the color stability of anthocyanins decreases during storage as temperature rises and exposure to light (Fig. 7).

At low temperatures $\left(-9^{\circ} \mathrm{C}\right.$ and $\left.4^{\circ} \mathrm{C}\right)$, the extracts retain their natural color while, at room temperature, the color is changed quite a lot, especially when storing under natural light conditions. A small change in the TAC was observed during 30 days of storage, with the losses calculated from $7.65 \%$ to $15.43 \%$

Table 3: Effect of extraction method on technical parameters and anthocyanin content obtained when extracting anthocyanins from leaves.

\begin{tabular}{lcc} 
& CE & MAE \\
Solvent-to-solid ratio (v/w) & $11.22 / 1$ & $10.83 / 1$ \\
Extraction time (minutes) & 27.21 & 4.39 \\
Anthocyanin content (mg.g $\left.\mathrm{g}^{-1}\right)$ & 25.61 & 30.60 \\
\hline
\end{tabular}

at $-9^{\circ} \mathrm{C}$ and $4^{\circ} \mathrm{C}$, respectively, which is in agreement with the results of Turker et al. [32] and Xiu-li et al. [33] in the study of the stability of anthocyanin-based extracts from purple sweet potato and fermented black carrot. They found that purple sweet potato extract displayed good thermal stability during 30 days of storage at $4^{\circ} \mathrm{C}$ and $20^{\circ} \mathrm{C}$ [33] and the highest anthocyanin retention was observed at $4^{\circ} \mathrm{C}$ storage temperature [32]. Hellström et al. [34] also confirmed that the half-life $\left(t_{1 / 2}\right)$ of anthocyanins in berry juices stored at different temperatures was much shorter at room temperature than at cold storage. In addition, at higher temperature storage (at $28^{\circ} \mathrm{C}$ and different conditions) in our experimental design, the TAC in leaves extracts degraded very quickly, and the losses were found to be more than $30 \%$. Increasing temperature can cause dissociation of the anthocyanin-copigment complex, thereby a loss of color [35]. Light exposure has been shown to be an important determinant of anthocyanins instability [36]. Our results indicated that light exposure can intensively weaken the

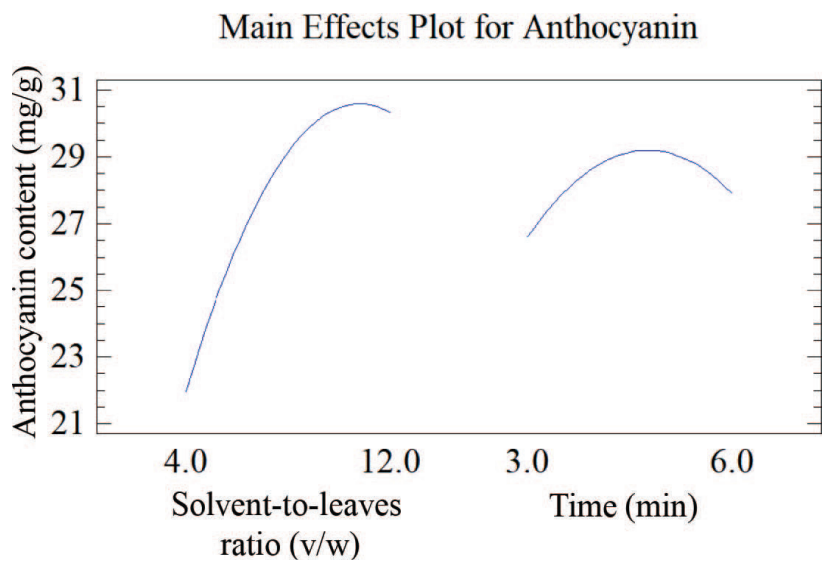

Figure 4: The influence of independent variables on anthocyanin content under MAE technique. 

L. Merr leaf 2022;10(02):146-153

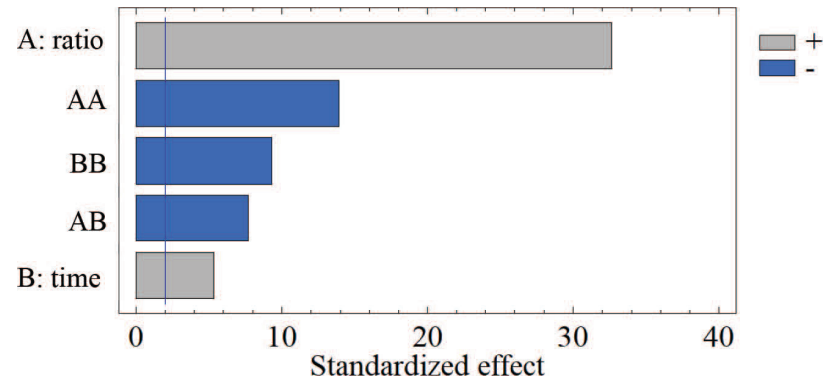

Figure 5: The standardized effect of factor on anthocyanin content under $\mathrm{CE}$ method. $A$ is solvent-to-leaves ratio (v/w); $B$ is extraction time (minute).

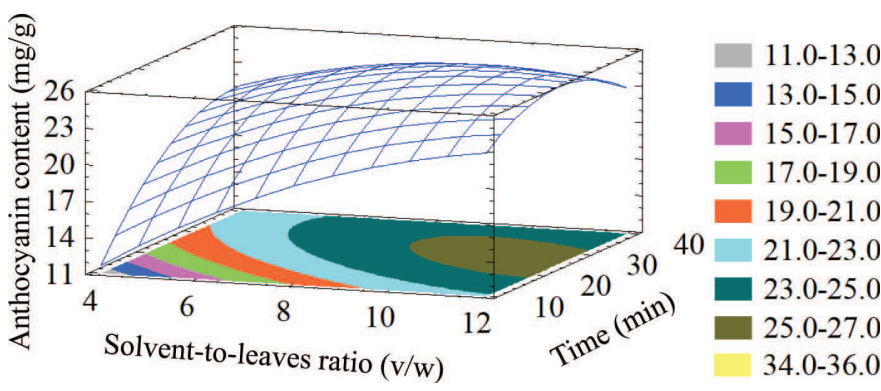

Figure 6: Estimated response surface plot for anthocyanin in extracts under MAE.

anthocyanins' stability. The resultant color stability of extract has also been affected. At the same temperature $\left(28^{\circ} \mathrm{C}\right)$, TAC losses of about $33.23 \%$ and $42 \%$ when the extract was stored in a dark place and normal light, respectively, during 30 days of storage were recorded. It was observed that a suitable condition for the storage of P. bivalvis L. Merr. leaves extract is in a dark place, which is in agreement with the results of Xiu-li et al. [33]. The degradation profiles of anthocyanins at different temperatures are illustrated in Figure 8.

It was found that the TAC decreased with the longer storage time. Degradation of the TAC in extracts during storage could be described by a zero-order kinetic model, as shown. A significant increase in the degradation rate $(k)$ was observed when the temperature increased (Table 4 ). The degradation rate constant $(k)$ increased almost twice when the temperature increased from $-9^{\circ} \mathrm{C}$ to $4^{\circ} \mathrm{C}$ and 2.33 times as temperature increased from $4^{\circ} \mathrm{C}$ to $28^{\circ} \mathrm{C}$. The half-life $\left(t_{1 / 2}\right)$ of anthocyanins at different temperatures storage was also calculated. From the data obtained, it was clearly shown that the value of $t_{1 / 2}$ significantly decreased from 221 to 114 and 49 days, which corresponded to an increase in temperatures from $-9^{\circ} \mathrm{C}$ to $4^{\circ} \mathrm{C}$ and $28^{\circ} \mathrm{C}$.

A significant increase in the half-life of anthocyanins could be obtained by lower temperature of storage $(p<0.05)$. The

Table 4: The degradation rate constant and half-life of anthocyanin in extracts during storage.

\begin{tabular}{ccccc}
$\begin{array}{c}\text { Storage } \\
\text { temperature }\left({ }^{\circ} \mathrm{C}\right)\end{array}$ & $\boldsymbol{k}\left(\mathrm{day}^{-1}\right)$ & $\boldsymbol{R}^{\mathbf{2}}$ & $\boldsymbol{t}^{\mathbf{1} / 2(\text { day })}$ & $\boldsymbol{E}_{\mathrm{a}}\left(\mathbf{k J} . \mathrm{mol}^{-1}\right)$ \\
-9 & 0.07 & 0.98 & 221 & \\
4 & 0.14 & 0.96 & 114 & 26.142 \\
28 & 0.32 & 0.99 & 49 & \\
\hline
\end{tabular}

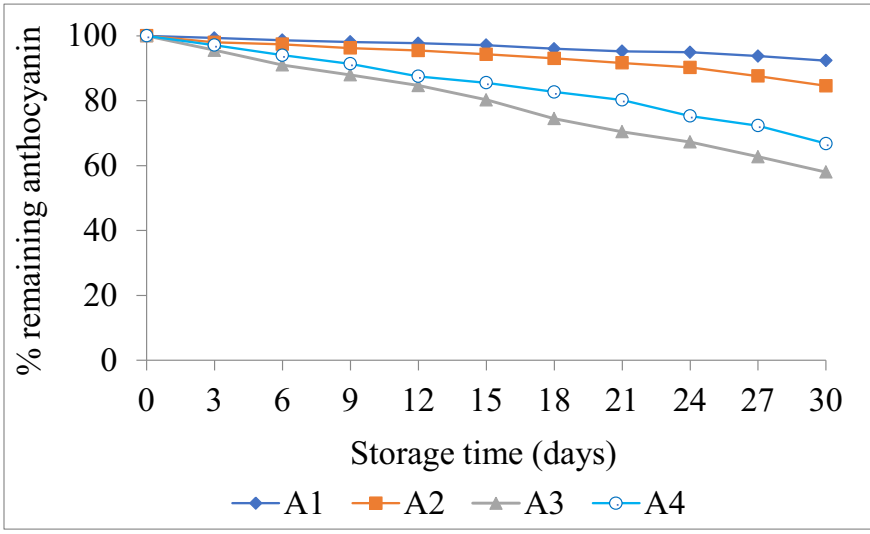

Figure 7: The remaining total anthocyanin versus time at different storage conditions. A1: sample was stored at $-9^{\circ} \mathrm{C}, \mathrm{A} 2$ : sample was stored at $4^{\circ} \mathrm{C}, \mathrm{A} 3$ : sample was stored at $28^{\circ} \mathrm{C}$ under normal condition, and $\mathrm{A} 4$ : sample was stored at $28^{\circ} \mathrm{C}$ and covered with aluminum foil and in a dark place.

highest retention of the TAC was found at $-9^{\circ} \mathrm{C}$ with a half-life of 221 days. A similar result was described by Wojdyło et al. [37]; the half-life value of anthocyanins in cloudy sour cherry ranged from 64.7 to 188.5 days at $4^{\circ} \mathrm{C}$. However, our obtained results showed a faster rate of anthocyanin degradation as compared with those of fermented carrot and black carrot juice samples stored at the same temperature $\left(4^{\circ} \mathrm{C}\right)$ as reported by some previous studies. Turker et al. [32] found that the highest anthocyanin retention in fermented carrot was observed at $4^{\circ} \mathrm{C}$ and a half-life between 231 and 239 days. Kurca et al. [38] reported that the $t_{12}$ value of the anthocyanin of black carrot juice concentrate at 64 Brix at $4^{\circ} \mathrm{C}$ was 1,505 days; it was much higher than our $t_{12}$ value. The differences between $t_{12}$ values may be due to the difference of order reaction [39]. Each compound displayed its own specific decomposition, related to sugar binding and storage temperature. Activation energy, $E_{\mathrm{a}}$, is the minimum energy that molecules must have in order to react to form products. The slope of the Arrhenius plot can be used to find the activation energy (Fig. 9). From this study, our activation energy value was calculated as $26.14 \mathrm{~kJ} \cdot \mathrm{mol}^{-1}$ which was lower than those reported for fermented black carrot anthocyanin $(11.11-11.64 \mathrm{kcal} / \mathrm{mol}$ or $\left.46.44-48.65 \mathrm{~kJ}^{-\mathrm{mol}^{-1}}\right)$ at $4{ }^{\circ} \mathrm{C}, 25^{\circ} \mathrm{C}$, and $40^{\circ} \mathrm{C}$ [32] and Hibiscus anthocyanin $\left(13-62.70 \mathrm{~kJ} \cdot \mathrm{mol}^{-1}\right)$ at $4^{\circ} \mathrm{C}$ and $30^{\circ} \mathrm{C}[40]$. Since a high activation energy value indicates a higher sensitivity of the reaction

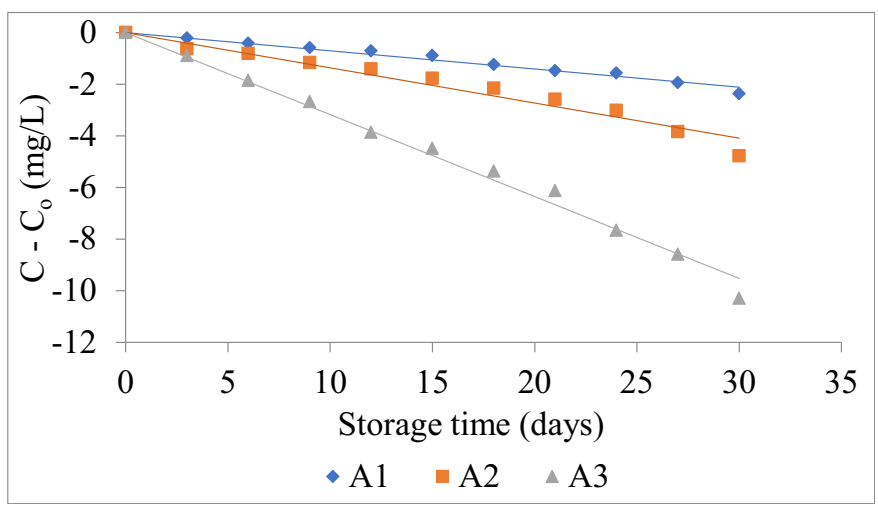

Figure 8: Degradation of anthocyanin content in extracts during storage. A1: sample was stored at $-9^{\circ} \mathrm{C}$; A2: sample was stored at $4^{\circ} \mathrm{C}$; A3: sample was stored at $28^{\circ} \mathrm{C}$. 


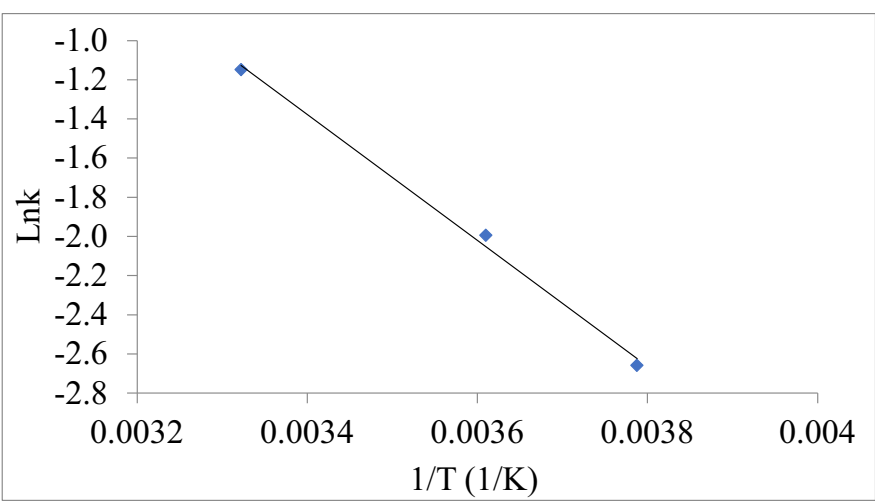

Figure 9: Arrhenius plot of change in TAC; $1 / \mathrm{T}(1 / \mathrm{K})$ versus Lnk.

rate to temperature, the degradation of anthocyanins in our leaves extract seems to be less susceptible to temperature elevation than that of fermented black carrot and Hibiscus anthocyanin.

\section{CONCLUSION}

Extraction conditions strongly affected the TAC in the extract from "lá cẩm" leaves. The results showed that the MAE technique improved the TAC obtained and reduced the extraction time. The half-life values obtained from the zero-order degradation kinetic model suggest that the P. bivalvis L. Merr. leaves extract should be kept at a low temperature for long-term storage or kept in the dark at room temperature for short-term use. The freezing temperature could be minimized in total anthocyanin degradation. The success of this research could open up many fruitful applications in different food sectors. This finding could be applied to increase the stability of natural colorants from the $P$. bivalvis L. Merr. (lá cẩm) leaves extract in the food and beverage industries where extraction and storage conditions are involved.

\section{AUTHOR CONTRIBUTIONS}

All authors made substantial contributions to conception and design, acquisition of data, or analysis and interpretation of data; took part in drafting the article or revising it critically for important intellectual content; agreed to submit to the current journal; gave final approval of the version to be published; and agree to be accountable for all aspects of the work. All the authors are eligible to be an author as per the international committee of medical journal editors (ICMJE) requirements/guidelines.

\section{FUNDING}

There is no funding to report.

\section{CONFLICTS OF INTEREST}

The authors report no financial or any other conflicts of interest in this work.

\section{ETHICAL APPROVALS}

This study does not involve experiments on animals or human subjects.

\section{PUBLISHER'S NOTE}

This journal remains neutral with regard to jurisdictional claims in published institutional affiliation.

\section{REFERENCES}

1. Tanaka Y, Ke NV. Edible wild plants of Vietnam: the bountiful garden. Orchid Press, Bangkok, Thailand, 2007.

2. Konczak I, Zhang W. Anthocyanins - more than nature's colours. J Biomed Biotechnol 2004;5:239-40; http://doi.org/10.1155/ S1110724304407013

3. Stoia M, Oancea S, Otto K, Hilma G. Antioxidant and antimicrobial activity of anthocyanins crude extracts: from nutraceuticals to phytopharmaceuticals. Conference: Phytopharm, Vienna, Austria, 91 p, 2013; http://doi.org/10.13140/2.1.2919.1366

4. Baharfar R, Azimi R, Mohseni M. Antioxidant and antibacterial activity of flavonoid-, polyphenol- and anthocyanin-rich extracts from Thymus kotschyanusboiss \& hohen aerial parts. J Food Sci Technol 2015;52(10):6777-83; http://doi.org/10.1007/s13197-015-1752-0

5. Khoo HE, Azlan A, Tang ST, Lim SM. Anthocyanidins and anthocyanins: colored pigments as food, pharmaceutical ingredients, and the potential health benefits. Food Nutr Res 2017;61(1361779):120; http://doi.org/10.1080/16546628.2017.1361779

6. Flórez N, Conde E, Domínguez H. Microwave assisted water extraction of plant compounds. J Chem Tech Biotech 2015;90(4):590 607; http://doi.org/10.1002/jctb.4519

7. Adetunji LR, Adekunle A, Orsat V, Raghavan V. Advances in the pectin production process using novel extraction techniques: a review. Food Hydrocoll 2017;62:239-50; http://doi.org/10.1016/j. foodhyd.2016.08.015

8. Ani TA, Calinescu I, Lavric V. Microwave extraction of active principles from medicinal plants. UPB Sci Bull B: Chem Mater Sci 2012;74(2):129-42.

9. Cacace JE, Mazza G. Optimization of extraction of anthocyanins from black currants with aqueous ethanol. J Food Sci 2003;68(1):240-8; http://doi.org/10.1111/j.1365-2621.2003.tb14146.x

10. Guisti MM, Wrolstad RE. Characterization and measurement of anthocyanins by UV-Visible spectroscopy. In: Wrolstad RE (ed.). Current protocols in food analytical chemistry. (F1.21-F1.2.13), John Wiley \& Sons, New York, NY, 2001; http://doi. org/10.1002/0471142913.faf0102s00

11. Charurungsipong P, Tangduangdee C, Amornraksa S, Asavasanti $\mathrm{S}$, Lin J. Improvement of anthocyanin stability in butterfly pea flower extract by co-pigmentation with catechin. In: E3S Web of Conferences, Thailand. pp 03008, vol. 141, 2020; http://doi. org $/ 10.1051 / \mathrm{e} 3$ sconf $/ 202014103008$

12. KırcaA, Cemeroğlu B. Degradation kinetics of anthocyanins in blood orange juice and concentrate. Food Chem 2003;81(4):583-7; http:/ doi.org/10.1016/S0308-8146(02)00500-9

13. Anderson OM, Fosse, T. Characterization of anthocyanins by NMR. In: Wrolstad RE., et al., (eds.). Handbook of food analytical chemistry, John Wiley \& Sons, New York, NY, 2005.

14. Baskaran A, Mudalib SKA, Izirwan I. Optimization of aqueous extraction of blue dye from butterfly pea flower. J Phys Conf Ser 2019;1358(1):012001.

15. Herodež ŠS, Hadolin M, Škerget M, Knez Ž. Solvent extraction study of antioxidants from Balm (Melissa officinalis L.) leaves. Food Chem 2003;80(2):275-82; http://doi.org/10.1016/S0308-8146(02)00382-5

16. Thuy NM, Ben TC, Minh VQ, Tai NV. Effect of extraction techniques on anthocyanin from butterfly pea flowers (Clitoria ternatea L.) cultivated in Vietnam. J Appl Biol Biotech 2021. Available via https:// jabonline.in/abstract.php?article_id $=625 \&$ sts $=2$.

17. Al-Farsi MA, Lee CY. Optimization of phenolics and dietary fibre extraction from date seeds. Food Chem 2008;108(3):977-85; http:// doi.org/10.1016/j.foodchem.2007.12.009

18. Mohamad M, Ali MW, Ahmad A. Modelling for extraction of major phytochemical components from Eurycoma longifolia. J Appl Sci 2010;10(21):2572-7; http://doi.org/10.3923/jas.2010.2572.2577

19. Xu B, Chang SK. Total phenolics, phenolic acids, isoflavones, and anthocyanins and antioxidant properties of yellow and black 
soybeans as affected by thermal processing. J Agric Food Chem 2008;56(16):7165-75; http://doi.org/10.1021/jf8012234

20. Xu DP, Li Y, Meng X, Zhou T, Zhou Y, Zheng J, et al. Natural antioxidants in foods and medicinal plants: extraction, assessment and resources. Int J Mol Sci 2017;18(1):96; http://doi.org/10.3390/ ijms 18010096

21. Marpaung AM, Djani DP, Rahmawati D. Anthocyanin from Bauhinia purpurea flower: extraction, color characteristics and stability. Indo Food Nutr Progr 2020;17(1):1-5; http://doi.org/10.22146/ifnp.52037

22. Pinelo M, Rubilar M, Jerez M, Sineiro J, Núñez MJ. Effect of solvent, temperature, and solvent-to-solid ratio on the total phenolic content and antiradical activity of extracts from different components of grape pomace. J Agr Food Chem 2005;53(6):2111-7; http://doi.org/10.1021/ jf0488110

23. Espada-Bellido E, Ferreiro-González M, Carrera C, Palma M, Álvarez JA, Barbero G, et al. Extraction of antioxidants from blackberry (Rubus ulmifolius L.): comparison between ultrasound-and microwaveassisted extraction techniques. Agronomy 2019;9(11):745.

24. Tsai PJ, Delva L, Yu TY, Huang YT, Dufosse L. Effect of sucrose on the anthocyanin and antioxidant capacity of mulberry extract during high temperature heating. Food Res Int 2005;38(8-9):1059-65; http:// doi.org/10.1016/j.foodres.2005.03.017

25. Alara OR, Abdurahman NH. Microwave-assisted extraction of phenolics from Hibiscus sabdariffa calyces: Kinetic modelling and process intensification. Indus Crops Pro 2019;528-35.

26. Zheng X, Wang X, Lan Y, Shi J, Xue SJ, Liu C. Application of response surface methodology to optimize microwave-assisted extraction of silymarin from milk thistle seeds. Separation Purif Tech 2009;70(1):34-40; http://doi.org/10.1016/j.seppur.2009.08.008

27. Liazid A, Guerero RF, Cantos E, Palma M, Barroso CG. Microwave assisted extraction of anthocyanins from grape skin. Food Chem 2011;124(3):1238-124; http://doi.org/10.1016/j. foodchem.2010.07.053

28. Felkai-Haddache L, Remini H, Dulong V, Mamou-Belhabib K, Picton $\mathrm{L}$, Madani $\mathrm{K}$, et al. Conventional and microwave-assisted extraction of mucilage from Opuntia ficus-indica Cladodes: physico-chemical and rheological properties. Food Bio Tech 2016;9(3):481-92; http:// doi.org/10.1007/s11947-015-1640-7

29. Pap N, Beszédes S, Pongrácz E, Myllykoski L, Gábor M, Gyimes E, et al. Microwave-assisted extraction of anthocyanins from black currant marc. Food Bio Tech 2013;6(10):2666-74; http://doi. org/10.1007/s11947-012-0964-9

30. Cardoso-Ugarte GA, Sosa-Morales ME, Ballard T, Liceaga A, San Martín-González MF. Microwave-assisted extraction of betalains from red beet (Beta vulgaris). LWT-Food Sci Tech 2014;59(1):27682; http://doi.org/10.1016/j.lwt.2014.05.025

31. Destandau E, Michel T, Elfakir C. Microwave-assisted extraction. In: Rostagno MA and Prado JM (ed.). Natural product extraction: principles and applications, $113 \mathrm{p}$, vol 21, 2013; http://doi. org/10.1039/9781849737579-FP001
32. Turker N, Aksay S, Ekiz HI. Effect of storage temperature on the stability of anthocyanins of a fermented black carrot (Daucuscarota var. L.) beverage: shalgam. J Agr Food Chem 2004;52(12):3807-13; http://doi.org/10.1021/jf049863s

33. Xiu-li HE, Xue-li LI, Yuan-ping LV, Qiang HE. Composition and color stability of anthocyanin-based extract from purple sweet potato. Food Sci Technol Campinas 2015;35(3):468-73; http://doi. org/10.1590/1678-457X.6687

34. Hellström J, Mattila P, Karjalainen RO. Stability of anthocyanins in berry juices stored at different temperatures. J Food Compo Anal 2013;31:12-9; http://doi.org/10.1016/j.jfca.2013.02.010

35. Bąkowska A, Kucharska AZ, Oszmiański J. The effects of heating, UV irradiation, and storage on stability of the anthocyanin-polyphenol copigment complex. Food Chem 2003;81(3):349-55; http://doi. org/10.1016/S0308-8146(02)00429-6

36. Cavalcanti RN, Santos DT, Meireles MAA. Non-thermal stabilization mechanisms of anthocyanins in model and food systems-an overview. Food Res Inter 2011;44(2):499-509; http://doi.org/10.1016/j. foodres.2010.12.007

37. Wojdyło A, Nowicka P, Teleszko M. Degradation kinetics of anthocyanins in sour cherry cloudy juices at different storage temperature. Processes 2019;7:367; http://doi.org/10.3390/pr7060367

38. Kirca A, Özkan M, Cemeroglu B. Effect of temperature, solid content and $\mathrm{pH}$ on the stability of black carrot anthocyanins. Food Chem 2007;101:212-8; http://doi.org/10.1016/j.foodchem.2006.01.019

39. Türkyılmaz M, Özkan M. Kinetics of anthocyanin degradation and polymeric colour formation in black carrot juice concentrates during storage. Int J Food Sci Technol 2012;47(11):2273-81; http://doi. org/10.1111/j.1365-2621.2012.03098.x

40. Gradinaru G, Biliaderis CG, Kallithraka S, Kefalas P, Garcia-Viguera C. Thermal stability of Hibiscus sabdariffa L. anthocyanins in solution and in solid state: effects of copigmentation and glass transition. Food Chem 2003;83(3):423-36; http://doi.org/10.1016/S03088146(03)00125-0

\section{How to cite this article:}

Thuy NM, Han DHN, Minh VQ, Tai NV. Effect of extraction methods and temperature preservation on total anthocyanins compounds of Peristrophe bivalvis L. Merr leaf. J Appl Biol Biotech 2022; 10(02):146-153. 